\title{
Why do we still need large scale clinical trial: the case of $n-3$ PUFA
}

\author{
Roberto Marchioli ${ }^{1,2}$ and Giacomo Levantesi ${ }^{1,3}$ \\ 1 Laboratory of Clinical Epidemiology of Cardiovascular Disease, Consorzio Mario Negri Sud, Chieti, Italy \\ ${ }^{2}$ Italian Society of Cardiology Research Center, Rome, Italy \\ ${ }^{3}$ Coronary Care Unit, Cardiologic Department, "S.Pio" Hospital Vasto, Chieti, Italy
}

\section{Edited by:}

George E. Billman, The Ohio State

University, USA

\section{Reviewed by:}

George E. Billman, The Ohio State

University, USA

Bill Harris, Health Diagnostic

Laboratory, USA

*Correspondence:

Roberto Marchioli, Laboratory of Clinical Epidemiology of

Cardiovascular Disease, Consorzio

Mario Negri Sud, Via Nazionale 8/A

Santa Maria Imbaro, Italy.

e-mail:marchioli@negrisud.it

\begin{abstract}
After the first reports about a protective effect on coronary heart disease (CHD) published more than 40 years ago, wide interest in the therapeutic use of $n-3$ polyunsaturated fatty acids ( $n-3$ PUFA) aroused. Since then, many studies and meta-analyses have reported a significantly reduced risk of $\mathrm{CHD}$ and $\mathrm{CV}$ death due to fish and $n-3$ PUFA intake. Some of the overviews reported a significant reduction of risk of sudden cardiac death, all-cause death, and nonfatal CV events. On the other side, recent clinical trials had mixed findings, raising concern about the consistency of the evidence on $n-3$ PUFA. We critically reviewed recent large clinical trials reporting data on the antiarrhythmic effects of $n-3$ PUFA in different clinical settings, i.e., patients with $\mathrm{CHD}$, heart failure, with implantable cardioverter defibrillator, and at risk of atrial fibrillation, in order to summarize the results which are available up to date and possibly give "substantiated" fuel to the debate on the conflicting results of $n-3$ PUFA.
\end{abstract}

\section{Keywords: $\boldsymbol{n}-\mathbf{3}$ polyunsaturated fatty acids, clinical trials, review}

\section{INTRODUCTION}

After the first report about a protective effect on coronary heart disease (CHD) published more than 40 years ago, wide interest in the therapeutic use of $n-3$ polyunsaturated fatty acids $(n-3$ PUFA) aroused (Bang et al., 1971; Bang and Dyerberg, 1972). Since then, many studies have been performed, increasing our knowledge on the cardiovascular (CV) effects of $n-3$ PUFA. Various meta-analyses have reported a significantly reduced risk of $\mathrm{CV}$ events, primarily due to reduction of $\mathrm{CHD}$ and $\mathrm{CV}$ death due to fish and n-3 PUFA intake (He et al., 2004; Leon et al., 2008; Marik and Varon, 2009; Mente et al., 2009). Some of the overviews reported a significant reduction of risk of sudden cardiac death (SCD; Leon et al., 2008; Marik and Varon, 2009), all-cause death (Marik and Varon, 2009), and non-fatal CV events (Marik and Varon, 2009). However, several questions remain open to date, e.g., the mechanisms accounting for the benefit observed in clinical studies as well as a possible heterogeneity of the effect in different populations. On the other side, recent clinical trials had mixed findings, raising concern about the consistency of the evidence on $n-3$ PUFA.

Among the many physiological effects which $n-3$ PUFA are supposed to have, the antiarrhythmic effect is the most interesting one but is challenging to be documented in humans because of the absence of reliable physiological measures or biomarkers to quantify the antiarrhythmic potential of $n-3$ PUFA on SCD.

We critically reviewed recent large clinical trials reporting data on the antiarrhythmic effects of $n-3$ PUFA in different clinical settings, i.e., patients with CHD (Marchioli et al., 2002; Yokoyama et al., 2007; Rauch et al., 2010), heart failure (HF; Tavazzi et al., 2008), with implantable cardioverter defibrillator (ICD; Leaf et al., 2005; Raitt et al., 2005; Brouwer et al., 2006), and at risk of atrial fibrillation (AF; Calo et al., 2005; Kowey et al., 2010; Nodari et al., 2011), in order to summarize the results which are available up to date and possibly give "substantiated" fuel to the debate on the conflicting results of $n-3$ PUFA.

\section{CORONARY HEART DISEASE}

The first intervention study suggesting an antiarrhythmic effect of $n-3$ PUFA was the Diet and Reinfarction Trial (DART) study carried out on 1989 (Burr et al., 1989). In 2033 post-myocardial infarction (MI) men, those advised to eat fat fish two to three times a week had a significant $29 \%$ reduction in fatal MI compared to those not advised so. This benefit appeared early after the start of the trial and was hypothesized to be due to a reduction of sudden death. Some years later, a decreased mortality and sudden death were observed in post-MI patients receiving a Mediterranean alpha-linolenic acid (ALA)-rich diet (de Lorgeril et al., 1994). In another trial, patients with suspected MI and receiving fish oil (2 $g n-3$ PUFA daily) or mustard seed oil (containing $2.9 \mathrm{~g}$ of ALA per day) experienced fewer sudden deaths than the placebo group (Singh et al., 1997). An analysis of the US Physician's Health Study, a prospective study on 20,551 male physician followed for up to 11 years, showed that fish consumption $\geq$ once per week was associated with a $52 \%$ reduction in the risk of SCD as compared with men with lower fish intake (Albert et al., 1998). Later, a new report from this study showed an inverse relationship between blood levels of long chain $n-3$ PUFA and risk of SCD (Albert et al., 2002).

The strongest evidence suggesting an antiarrhythmic effect of n-3 PUFA was provided by GISSI-Prevenzione, an open-label, randomized, controlled trial performed to test the efficacy of an oral administration of $n-3$ PUFA ( $1 \mathrm{~g}$ daily) and vitamin $\mathrm{E}$ on 
morbidity and mortality in 11,323 Italian patients with recent ( $\mathrm{MI}<3$ months; Gruppo Italiano per lo Studio della Sopravvivenza nell'Infarto miocardico, 1999). After 3.5 years of followup, $n-3$ PUFA therapy significantly reduced the first combined, primary endpoint (death, non-fatal myocardial, and non-fatal stroke) by $15 \%$ (95\% confidence interval, CI: $3-27, P=0.02)$ as well as the co-primary endpoint (cardiovascular death plus nonfatal MI plus non-fatal stroke) by $20 \%$ (95\% CI: 6-32, $P=0.006)$ as compared to the control group. Secondary analyses of the components of the primary endpoints showed that almost all the benefit observed in the combined endpoints was attributable to the reduction in fatal events: total mortality 20\%, (95\% CI: 6-23\%); CV death 30\% (95\% CI: 13-44\%); CHD death 35\% (95\% CI: $16-$ $49 \%$ ); and SCD 44\% (95\% CI: $24-60 \%$ ). An intention-to-treat analysis of GISSI-Prevenzione, adjusted for interaction between treatments, was aimed at assessing the time course of benefit on fatal events. It showed an early divergence of the survival curves for $n-3$ PUFAs and control groups after randomization, with total mortality being significantly lowered after only 3 months of treatment (RR 0.59, 95\% CI: 0.36-0.97; $P=0.037$; Marchioli et al., 2002). Likewise, the reduction in risk of SCD was already statistically significant at 4 months (RR 0.47; 95\% CI: 0.219-0.995; $P=0.048$ ). A similarly significant, although delayed, pattern was observed for $\mathrm{CV}$, cardiac, and CHD deaths after 6-8 months of treatment. In agreement with previous evidence coming from both experimental and human studies, such findings suggested that the early benefits of $n-3$ PUFA may be due to their antiarrhythmic activity (McLennan et al., 1992, 1993; Kang and Leaf, 1994, 1995, 1996; Kang et al., 1995; Sellmayer et al., 1995; Siscovick et al., 1995; Xiao et al., 1995, 1997, 1998; Christensen et al., 1997; Billman et al., 1999).

GISSI-Prevenzione trial had several strengths. It was adequately sized (the largest prospective controlled trial that investigated the effect of a dietary-derived drug on CV events) in a population of patients at high-risk of arrhythmia, with a reliable statistical power to show that $n-3$ PUFA could decrease hard endpoints of morbidity and mortality in a clinically and statistically significant manner. As to clinical relevance, it is worth noting that for every 1000 post-MI patients treated for 1 year with $1 \mathrm{~g}$ daily of $n-3$ PUFA, 5.7 lives were saved. Such protective effect with $n-3$ PUFA treatment observed in GISSI-Prevenzione is comparable in the magnitude to the results of other drugs which are now considered therapeutic cornerstone in cardiovascular prevention. For instance, in the LIPID trial, 5.2 lives could be saved treating with pravastatin for 1 year 1000 patients with hypercholesterolemia and CHD (The Long-Term Intervention with Pravastatin in Ischaemic Disease (LIPID) Study Group, 1998). Although some changes in the management of post-MI patients occurring over years have to be considered, many aspects of GISSI-Prevenzione are reassuring as to the transferability of the results to clinical practice for post-MI patients,: (a) the trial was very large and performed in the framework of a "usual care" clinical setting, (b) it was carried out in a country-wide network of hospitals within the Italian national public health service, and (c) had a pragmatic design aimed at not interfering with daily clinical practice. It might be also argued that in populations at high $\mathrm{CV}$ risk, such as those with a western lifestyle, $n-3$ PUFA might have greater benefit than in the Italian population, known to be at low risk for CHD mainly for the Mediterranean dietary habits (Marckmann and Gronbaek, 1999). The benefit of $n-3$ PUFA treatment can be considered as additive to those of recommended pharmacological treatments and lifestyle interventions. Indeed, patients enrolled in GISSI-Prevenzione received $n-3$ PUFA treatment on the top of preventive pharmacological treatments, including aspirin, betablockers, angiotensin-converting enzyme (ACE) inhibitors and cholesterol-lowering drugs, as well as of lifestyle interventions leading at the end of the trial to a positive modification of dietary habits with increase of the (already relatively high) intake of olive oil, fruit, vegetables, and fish (Barzi et al., 2003).

Recent randomized clinical trials did not confirm the antiarrhythmic effect of $n-3$ PUFA. The Japan EPA Lipid Intervention Study (JELIS; Yokoyama et al., 2007) was a large scale trial conducted in 18,000 hypercholesterolemic Japanese patients who were randomized to $n-3$ PUFA treatment $(1.8 \mathrm{~g} /$ day) in combination with statin vs. statin alone. After a mean follow-up of 4.6 years, the patients in the $n-3$ PUFA group experienced a reduction of $19 \%$ of CHD events. The benefit of $n-3$ PUFA was limited to non-fatal CHD events, particularly unstable angina, whilst the effect on fatal events was not significant, particularly on SCD. Such apparent lack of the antiarrhythmic effect in this population of patients could be related to some specific aspects of JELIS. Firstly, the assumption of reaching a statistical power of $80 \%$ for detecting a relative reduction of $25 \%$ in the primary endpoint was respected, but the rate of SCD (i.e., a secondary outcome measure) in the JELIS population was extremely low. Only 35 of the 18,645 participants $(0.19 \%)$ in JELIS experienced a SCD during 5 years of follow-up. As a result the study lacked sufficient power, to detect an effect on mortality in general and specifically on SCD (statistical power of 13, 7, and $5 \%$ to detect a relative reduction of 30,20 , and $10 \%$ of the risk in SCD, respectively, Table 1). Another relevant aspect of JELIS was the administration of $1.8 \mathrm{~g}$ daily of eicosapentaenoic acid (EPA) on the top of a high dietary intake of $n-3$ PUFA. A pooled analysis of prospective and randomized studies suggested the existence of a dose-response curve for the antiarrhythmic effect of $n-3$ PUFA on SCD, which seems to have a steep slope at modest levels of $n-3$ PUFA intake ( $<750 \mathrm{mg}$ ) and a plateau thereafter, higher doses of $n-3$ PUFA having been hypothesized not having further beneficial effects on SCD (Mozaffarian and Rimm, 2006). Because of the high fish intake (e.g., median $900 \mathrm{mg} /$ day) of Japanese people (Iso et al., 2006), this "threshold" effect might play a role in the JELIS results, e.g., by magnifying anti-atherosclerotic, anti-inflammatory, and plaque stabilizing effects of the high daily supplement of $n-3$ PUFA (1800 mg) while the benefit on arrhythmic events was not detectable due to the low rate of such events in this population. Like in the case of JELIS, the lack of clinical benefit reported in a previous study evaluating the effect of $4 \mathrm{~g}$ /day of $n-3$ PUFA, compared to corn oil, in 300 post-MI patients (4-8 days; Nilsen et al., 2001), may be due to both a "threshold effect" as well as to an insufficient study power due to the low event rate observed in the study.

In 2010 the results of the OMEGA trial have been published. The study was a randomized, double-blind, placebo-controlled, multicentre trial, testing the effect of $n-3$ PUFA $(1000 \mathrm{mg} /$ day for 12 months) on the rate of SCD in 3851 patients with MI 


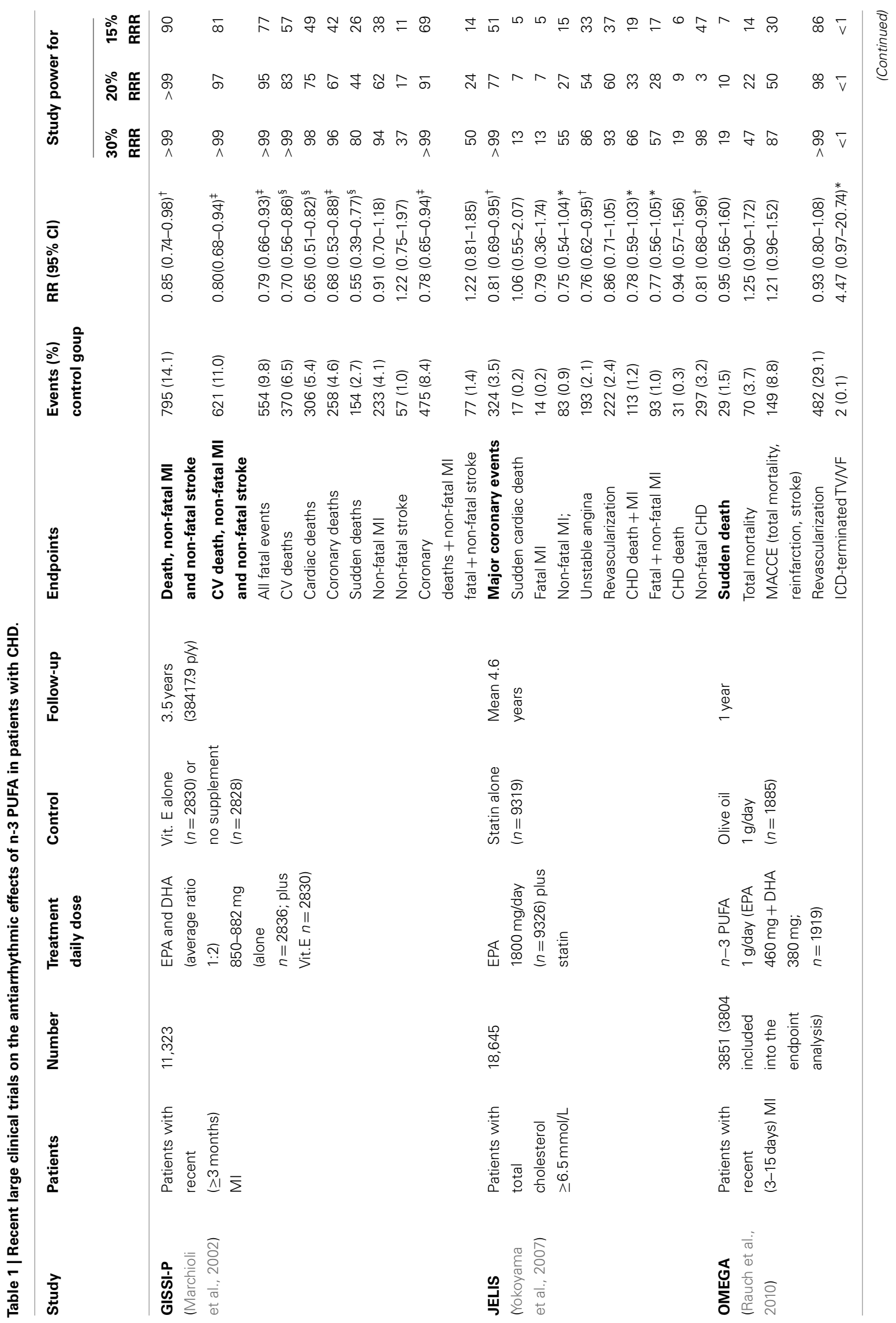




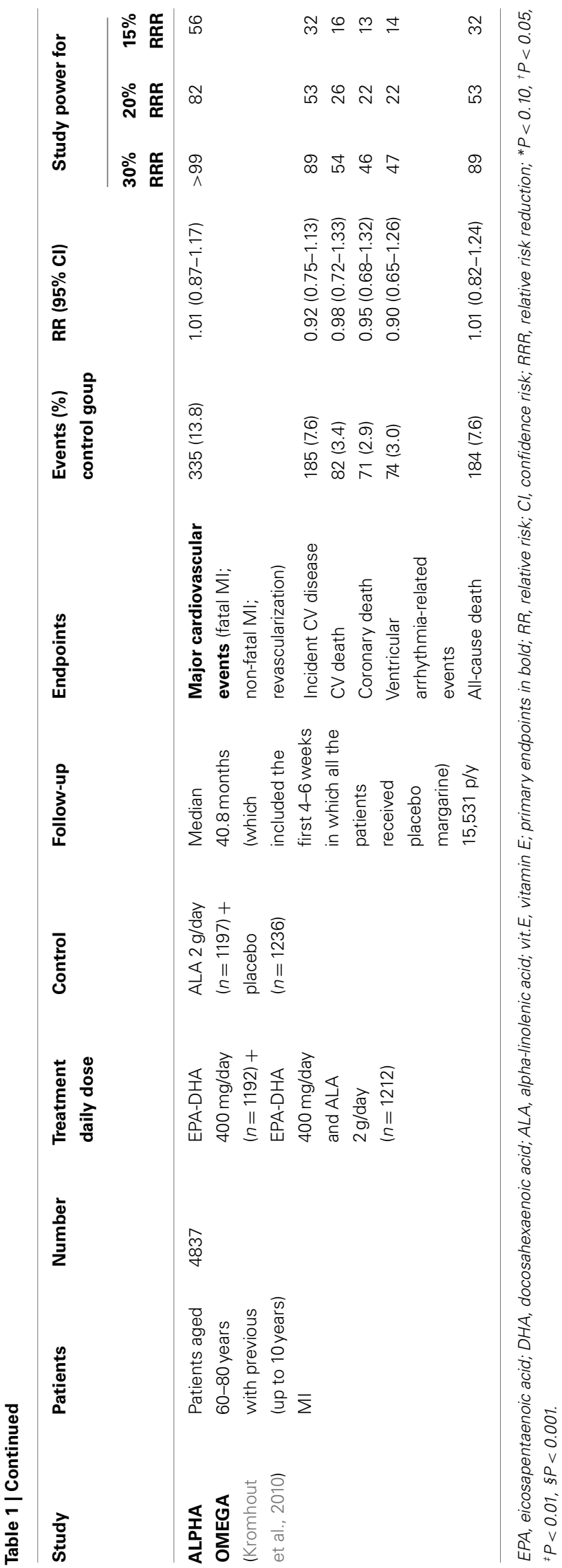

in the previous 3-14 days (Rauch et al., 2006, 2010). Secondary endpoints of OMEGA included total mortality and non-fatal $\mathrm{CV}$ events. Also, OMEGA showed no difference in the incidence of SCD between $n-3$ PUFA and placebo groups ( 1.5 vs. $1.5 \%$; $P=0.84)$. No difference with regard to secondary endpoints was found (total mortality 4.6 vs. $3.7 \%$; $P=0.18$; major cerebrovascular and CV events 10.4 vs. $8.8 \%$; $P=0.1$; revascularization in survivors 27.6 vs. $29.1 \% ; P=0.34$ ). Some methodological aspects of the OMEGA trial deserve to be considered. It was assumed that the proportion of SCD during the study should have been $44 \%$ of total deaths, therefore resulting in a SCD rate of 3.5\% in the control group at the end of the study. The observed incidence of SCD was lower (1.5\% in both groups), i.e., less than the half of the expected one, thus making the trial underpowered to detect an antiarrhythmic effect of $n-3$ PUFA (Table 1). Another aspect to be considered is the treatment of post-MI patients enrolled in OMEGA Study. Acute revascularization was performed in $81 \%$ of patients. Short- and long-term guideline-driven medication was administered in the vast majority of patients: b-blockers, ACE inhibitors/angiotensin receptor blockers (ARB), statins, acetylsalicylic acid, and clopidogrel were prescribed to $94,91,94,95$, and $88 \%$ of patients, respectively. The large use of guideline-based therapy after MI may have contributed to the low rate of fatal events, so reducing the room for improvement due to $n-3$ PUFA treatment, and, on the other hand, may also reduce the transferability of OMEGA results to the treatment of post-MI patients that, to date, still appear substantially different in clinical practice (Kotseva et al., 2009a,b).

The results of Alpha Omega Trial have been published a few weeks after the publication of OMEGA (Kromhout et al., 2010). Alpha Omega was a multicenter, double-blind, placebo-controlled trial testing the effects of $n$-3 PUFA on the rate of cardiovascular events among 4837 patients, 60 through 80 years of age, who have had a MI. Patients were randomly assigned to use for 40 months one of four types of margarine enriched with marine n-3 PUFA with a targeted additional daily intake of (a) $400 \mathrm{mg}$ of a combination of EPA and docosahexaenoic acid (DHA); (b) plant-derived $n-3$ PUFA, with a targeted additional daily intake of $2 \mathrm{~g}$ of alpha-linolenic acid (ALA); (c) marine ( $400 \mathrm{mg} /$ day) plus plant-derived ( $2 \mathrm{~g} /$ day) $n-3$ PUFA; (e) placebo. Neither marinenor plant-derived $n-3$ PUFA reduced the primary endpoint, i.e., the rate of major $\mathrm{CV}$ events, including fatal and non-fatal CV events and cardiac interventions (hazard ratio, HR with EPADHA, $1.01 ; 95 \%$ CI: $0.87-1.17 ; P=0.93$; HR with ALA, $0.91 ; 95 \%$ CI: $0.78-1.05 ; P=0.20) . n-3$ PUFA did not reduce the secondary endpoints, including ventricular arrhythmia-related events (SCD, fatal and non-fatal cardiac arrest, and placement of implantable cardioverter-defibrillators; HR with EPA-DHA, 0.90; 95\% CI: $0.65-1.26 ; P=0.55$; HR with ALA, 0.79 ; 95\% CI: $0.79-1.19$; $P=0.16$ ). Alpha Omega was a factorial trial and therefore only the two-way analyses comparing patients who received EPA-DHA to those not receiving marine $n-3$ PUFA as well as comparing patients who received ALA to those not receiving plant-derived n-3 PUFA were published. In the former case, 2404 patients with a mean daily supplementation of EPA-DHA of 400 mg plus a mean daily supplementation of ALA of $1008 \mathrm{mg}$ was compared to 2433 patients with a mean daily supplementation of ALA of $984 \mathrm{mg}$. 
In the latter case, 2409 patients with a mean daily supplementation of EPA-DHA of $201 \mathrm{mg}$ plus a mean daily supplementation of ALA of $2000 \mathrm{mg}$ was compared to 2428 patients with a mean daily supplementation of EPA-DHA of $196 \mathrm{mg}$. In other words, the effect of $n-3$ PUFA was not compared with a pure "placebo." The assessment of the effect of $n-3$ PUFA was likely to be biased because all the patients were receiving $n-3$ PUFA and in the case of marine $n-3$ PUFA the comparison was between two groups receiving approximately a total of 1.4 vs. $1.0 \mathrm{~g}$ of $n-3$ PUFA. The administration of $n-3$ PUFA in all patients of the Alpha Omega trial has made the results difficult to interpret and might have obscured the antiarrhythmic effect of $n-3$ PUFA if a threshold for the antiarrhythmic effect truly exists (de Lorgeril et al., 1994; Leaf, 1999; Zatonski et al., 2008). More recently the results of SU.FOL.OM3 study have been published (Galan et al., 2010). Among 1863 patients with CHD, neither a treatment with $n-3$ PUFA ( $600 \mathrm{mg} /$ day), nor treatment with $\mathrm{B}$ vitamins was associated with a significant effect on the occurrence of hard coronary events, a composite endpoint including sudden death, after a mean follow-up of $4.2 \pm 1.0$ years. No information on sudden death was provided in this study.

\section{HEART FAILURE}

The GISSI-Prevenzione results showed that systolic dysfunction was associated with elevated risk of SCD and with a consistent benefit from $n-3$ PUFA (Macchia et al., 2005). This was the core hypothesis of the GISSI-HF Trial, a randomized, placebocontrolled trial investigating the efficacy of $n-3$ PUFA (850$882 \mathrm{mg}$ EPA and DHA daily as ethyl ester compared to placebo) in 6975 patients who had clinical evidence of HF, classified as NYHA class II-IV, followed for a median of 3.9 years (Tavazzi et al., 2004, 2008). Statistically significant risk reductions in the two co-primary endpoints were observed in $n-3$ PUFA treated patients: 9\% (adjusted HR 0.91; 95\% CI: 0.833-0.998; $P=0.041$ ) and $8 \%$ (adjusted HR 0.92; 95\% CI: 0.849-0.999; $P=0.009$ ) for mortality and mortality plus admission to hospital for CV reason, respectively (Table 2 ). It might be argued that the benefit showed by $n-3$ PUFA in HF patients is only marginal, being modest as the amount of relative risk reduction was modest. Actually, due to the high mortality and hospitalization rates in HF patients, the relative risk reduction observed in GISSI-HF can be translated into an absolute benefit of 18 deaths avoided and 17 prevented CV hospitalizations for every 1000 patients treated for 3.9 years with $n-3$ PUFA, i.e., a not trivial benefit as compared to statins and ACE-inhibitors in high-risk populations (Yusuf et al., 2000; Heart Protection Study Collaborative Group, 2002). The main study results were consistent with those of the secondary analyses, which were predefined in the study protocol, for (a) baseline characteristics, (b) secondary outcomes, and (c) per-protocol analysis in the 4994 patients who were compliant to experimental treatments. Worsening of HF and presumed arrhythmic death accounted for $62 \%$ of all deaths and were lower in the $n-3$ PUFA as compared to placebo group. Almost half of the absolute reduction of risk of death due to $n-3$ PUFA treatment was attributable to the reduction of ventricular arrhythmias (mortality: $0.9 \%$ out of $1.8 \%$; first CV hospitalization: $1.0 \%$ out of $1.7 \%$ ). Moreover, the rate of total major ventricular arrhythmias, defined as the occurrence of arrhythmic death or hospitalization due to ventricular arrhythmias, was significantly reduced early after the start of treatment in the 3 PUFA group (Marchioli et al., submitted). These findings support the idea that also in the clinical setting of HF $n-3$ PUFA may exert their antiarrhythmic effect. In addition, the benefit in both co-primary endpoints (mortality and hospitalization) suggests that $n-3$ PUFA might positively affect the pathophysiologic mechanisms leading to the progression of $\mathrm{HF}$ (Marchioli et al., 2009; Ghio et al., 2010). GISSI-HF Trial had some weaknesses and limitations. The patients enrolled in the GISSIHF trial were already treated with guideline-based therapies for HF, so the benefit of $n-3$ PUFA can be considered as additive to the one determined by recommended treatments. Moreover, GISSI-HF trial adopted a pragmatic strategy, representing what happens in real-world settings of clinical practice. This assures the transferability of the GISSI-HF results to all patients with HF and suggest to not consider a limitation the apparent high percentages of patients who were not fully compliant with experimental treatments (by the end of the study $28.7 \%$ in the $n-3$ PUFA group and $29.6 \%$ in the placebo group). Although the observed benefit was lower than expected, it is comparable to the one obtained by the use of chronic preventive treatments in other clinical settings (Yusuf et al., 2000; Heart Protection Study Collaborative Group, 2002). On the other side, the high percentage of fully treated patients may have left limited room to further improvement. The low number of patients with preserved left ventricular ejection fraction $(<10 \%)$ may be partially considered as a limitation since it precluded to perform a reliable assessment of the effect of $n-3$ PUFA in this subgroup of patients.

\section{PATIENTS WITH IMPLANTABLE CARDIOVERTER DEFIBRILLATOR}

Few studies evaluated the antiarrhythmic effect of $n-3$ PUFA in patients with ICD, reporting mixed results. Two hundred patients with a recent episode of sustained ventricular tachycardia (VT) or ventricular fibrillation (VF) and implanted ICD were randomly assigned to receive $n-3$ PUFA, $1.8 \mathrm{~g}$ /day, or placebo in trial by Raitt et al. (2005) At a median follow-up of 718 days, $n-3$ PUFA did not prevent episodes of VT or VF. Overall, $n-3$ PUFA treatment was associated with a trend toward a higher incidence of the primary endpoint (time to ICD therapy for VT/VF; $P=0.19$ ), a significant increased rate of recurrent episodes of VT/VF $(P<0.001)$ and, in patients with VT as the qualifying entry rhythm, a significant increase in the primary endpoint $(P=0.007)$.

One year after this first trial, the results of The Study on Omega3 Fatty acids and ventricular Arrhythmia (SOFA) have been published (Brouwer et al., 2006). The SOFA trial was a randomized, parallel, placebo-controlled, double-blind study evaluating the effect of $n-3$ PUFA $2 \mathrm{~g}$ /day for a median period of 356 days, on appropriate ICD intervention for VT or VF, or all-cause death in 546 patients with ICD and prior documented malignant VT or VF. No statistically significant protective effect in $n-3$ PUFA group was shown (HR 0.86; 95\% CI: 0.64-1.16; $P=0.33$ ).

As to the results of these two trials, some aspects of study design have to be considered. The first point is the type of population enrolled in these studies. Approximately $23 \%$ of patients in the trial of Raitt et al. (2005), and the 30\% in SOFA had no history 


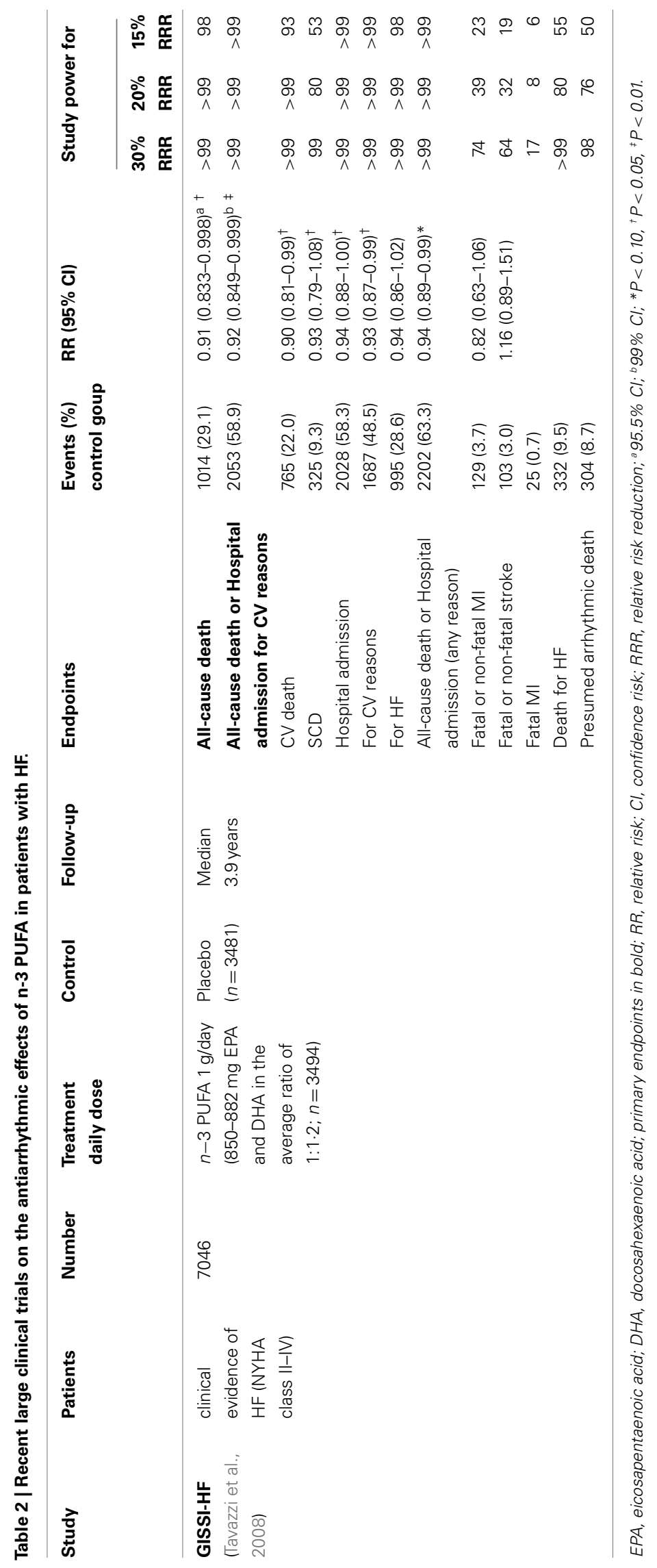


of CHD. The best evidence for the antiarrhythmic action of $n-3$ PUFA has been produced by experimental work performed in ischemia-mediated animal models and in clinical trials carried out in post-MI patients, in which ischemia-triggered arrhythmias may be predominant. Consequently, it has been hypothesize that $n-3$ PUFA may have a more favorable effect in patients in whom the specific clinical setting and underlying arrhythmogenic mechanisms of initiation and propagation may be more susceptible to the antiarrhythmic effects of $n-3$ PUFA (Leaf et al., 2003). The second aspect is the primary endpoint used in ICD trials, i.e., VT or VF. It certainly may address the influence of $n-3$ PUFA on the risk of ventricular arrhythmias, however it might not be the ideal surrogate for the risk of sudden death. Although VT may frequently degenerate in VF and consequently in a sudden death, the spontaneous resolution of this ventricular arrhythmia is not uncommon. We cannot exclude that the treatment with n-3 PUFA might increase this favorable event, impossible to be showed in patients with ICD because of the device intervention. Moreover caring physicians were allowed to program ICD as more appropriate for their patients, so it has to be taken into consideration that this may represent a possible bias. Another aspect to be considered is the statistical power of the two studies. The power of trial by Raitt was significantly weakened by the low event rate observed in the placebo group as compared with the expected one. In addition, the observed reduction of events was lower than expected (Table 3). The total event rate of the primary endpoint observed in SOFA (33\%) was close to the expected one (35\%), but the observed efficacy of $n-3$ PUFA was lower than the expected one that was used for sample size calculation. Accordingly, SOFA had a $69 \%$ power to detect a $30 \%$ event reduction, so it is not surprising that this study did not detect a significant reduction in the primary endpoint (Table 3).

At variance with these two studies, in the FAAT study (Leaf et al., 2005 ) the administration of $2.6 \mathrm{~g} /$ day of $n-3$ PUFA vs. placebo in 402 patients at high-risk for fatal ventricular arrhythmias showed a trend toward a reduction of the primary endpoint (risk reduction of $-28 \%$ of the time to the first ICD event for VT or VF, or death from any cause; $P=0.057)$. Although the choice to include all-cause death in the primary endpoint might be criticized, when probable and definite episodes of VT or VF were used as outcome measure, a statically significant relative risk reduction of $31 \%$ was obtained ( $P=0.033$; Leaf et al., 2005).

Two meta-analyses of data collected in these three trials did not support a protective effect of $n-3$ PUFA on cardiac arrhythmias. The first meta-analysis showed a significant heterogeneity between trials, and no effect of $n-3$ PUFA on the relative risk of ICD discharge (RR 0.93; 95\% CI: 0.70-1.24; Jenkins et al., 2008). The second meta-analysis, confirmed the existence of a considerable heterogeneity between the trials, and showed no convincing protective effect of $n-3$ PUFA on time to first confirmed VF or VT combined with death (RR 0.90; 95\% CI: 0.67-1.22), although the HR for the subgroup of patients with coronary artery disease at baseline tended toward a protective effect (RR 0.79; 95\% CI: 0.60-1.06; Brouwer et al., 2009).

The results of a GISSI-HF sub-study assessing the antiarrhythmic effect of $n-3$ PUFA in 566 patients with HF enrolled who had received an ICD for secondary or primary prevention of VF or VT have been recently published (Finzi et al., 2011). The primary endpoint (defined as time to first appropriate ICD discharge for VT/VF; adjusted $\mathrm{HR}=0.80,95 \% \mathrm{CI}$ : $0.59-1.09, P=0.152$ ), and the number of ICD discharges were not significantly altered $(P=0.30)$ by $n-3$ PUFA treatment.

The meta-analysis of these four trials on $n-3$ PUFA in patients with implanted ICD did not demonstrate a significant antiarrhythmic effect of $n-3$ PUFA (OR 0.82; 95\% CI: 0.67-1.01; $P=0.06$; Figure 1).

\section{PATIENTS AT RISK OF SUPRAVENTRICULAR TACHYARRHYTHMIAS}

Although results of observational studies suggested positive effects of $n-3$ PUFA in reducing the number of episodes as well as the burden of atrial tachyarrhythmia (Biscione et al., 2005), randomized control studies showed discrepant results (Table 4). An open-label, prospective, randomized, controlled trial with parallel groups, tested the effect of $2 \mathrm{~g}$ /day of $n-3$ PUFA on the development of AF in the postoperative period in 160 patients undergoing coronary artery by-pass grafting (CABG; Calo et al., 2005). Its results showed that $n-3$ PUFA administration before and during hospitalization substantially reduced the incidence of postoperative AF by $54.4 \%$ and was associated with a shorter hospital stay as compared the control group. In 199 patients with persistent AF treated with amiodarone and a renin-angiotensinaldosterone system inhibitor, the addition of $n-3$ PUFAs $2 \mathrm{~g}$ /day improved the probability of the maintenance of sinus rhythm at 1 year after direct current cardioversion (Nodari et al., 2011). At variance with the previous study, a prospective, randomized, double-blind, placebo-controlled, parallel-group multicenter trial involving 663 outpatient participants with previous confirmed symptomatic paroxysmal $(n=542)$ or persistent $(n=121) \mathrm{AF}$ reported no difference between treatment groups $(n-3$ PUFA $8 \mathrm{~g}$ /day or placebo for the first 7 days; $n-3$ PUFA $4 \mathrm{~g} /$ day or placebo thereafter through week 24) for recurrence of symptomatic AF in the paroxystic AF stratum (HR, 1.15; 95\% CI: $0.90-1.46 ; P=0.26)$, in the persistent AF stratum (HR, 1.64;95\% CI: $0.92-2.92 ; P=0.09$ ), and in both strata combined (HR, 1.22; 95\% CI: 0.98-1.52; $P=0.08$; Kowey et al., 2010).

A recent systematic review and meta-analysis of published randomized trial regarding $n-3$ PUFA supplementation for AF prevention on 1955 patients showed a significant heterogeneity among the studies $[P=0.002, I(2)=65.0 \%]$ and did not find a significant reduction in the risk for AF (OR 0.81, 95\% CI: 0.57-1.15; $P=0.24$; Liu et al., 2011).

The discrepant results on the benefit of $n-3$ PUFA in preventing supraventricular tachyarrhythmia in the above discussed trials may be due to several reasons. The role of several patient characteristics were probably underestimated.

Left atrial dimension, AF duration, recurrent episodes of AF, which reduced the possibilities of restore or maintain a stable sinus rhythm (Suzuki et al., 2011; Pisters et al., 2012), were nor included among inclusion criteria neither in subgroup analysis in all but one of the studies. Nodari et al. (2011) showed that the main correlates of AF recurrence were, other than $n-3$ PUFA, the duration of AF before randomization, left atrial dimension, and left ventricular ejection fraction, suggesting that atrial remodeling may play 


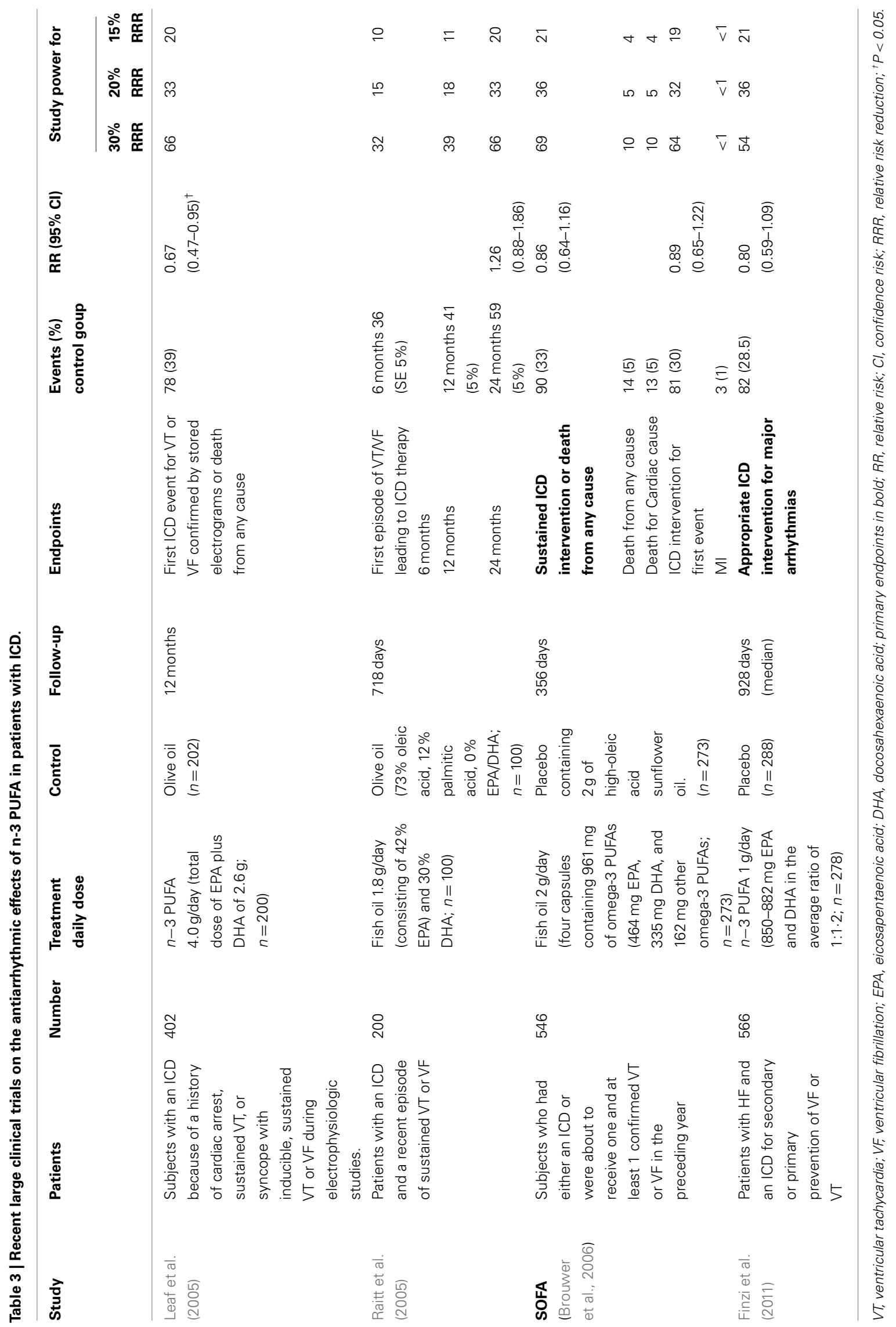




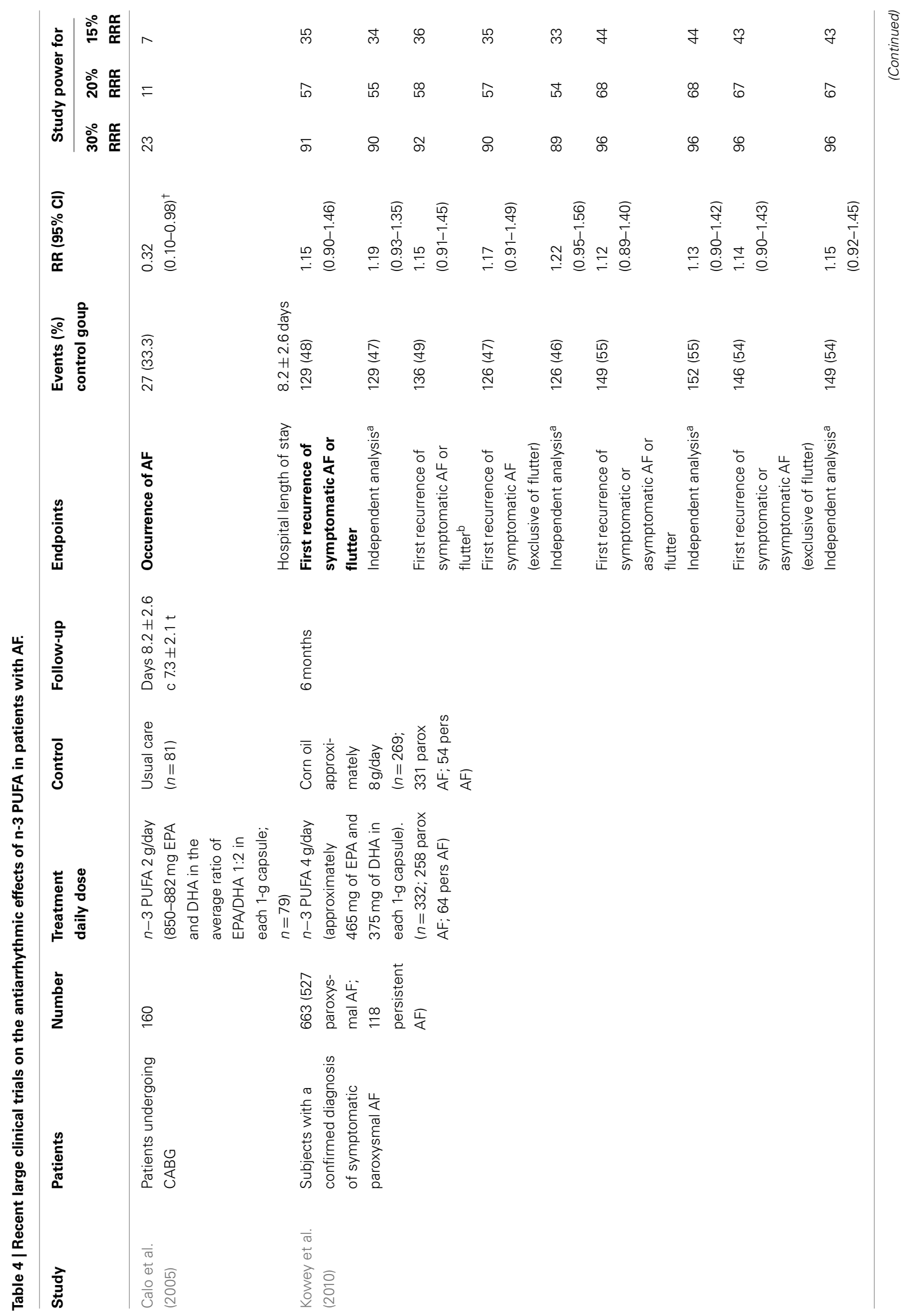




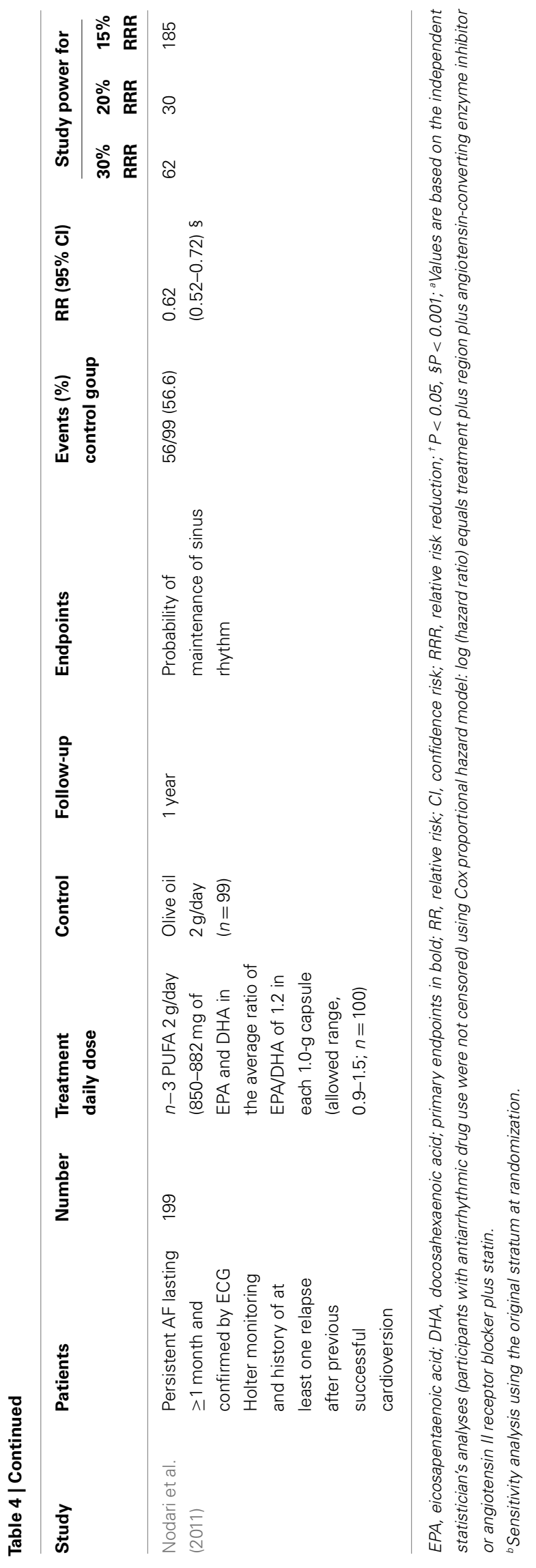

a role in this clinical setting. Similarly to the case of drugs inhibiting renin-angiotensin system, clinical success in restoring sinus rhythm is likely to be achievable only before the underlying atrial remodeling may have gone too far to be reversed (Savelieva et al., 2011). Baseline plasma levels of $n-3$ PUFA may have influenced the antiarrhythmic effect of oral supplementation (Skuladottir et al., 2011), and the use of new-onset, postoperative AF may not be the ideal model to assess the effect of $n-3$ PUFA on new-onset AF.

To date, as Camm and Savelieva (2011) affirmed in their editorial comment to the Nodari's article, the antiarrhythmic effect of $n-3$ PUFA in AF has not been demonstrated in randomized clinical trial. A large scale randomized controlled trial testing the effect of $n-3$ PUFA on supraventricular arrhythmias in patients undergoing to cardiac surgery is currently ongoing (Mozaffarian et al., 2011). Its results will increase our knowledge on the antiarrhythmic effects as well as on tolerability of $n-3$ PUFA in this clinical setting.

\section{REVIEWS AND META-ANALYSES}

The effect of $n-3$ PUFA on cardiovascular events and SCD has been analyzed in some reviews and meta-analyses.

A Cochrane review (Hooper et al., 2004) and a meta-analysis (Hooper et al., 2006) did not find a benefit of $n-3$ PUFA administration. The Cochrane review (Hooper et al., 2004), which included 89 studies (48 randomized controlled studies and 41 cohort studies), found that $n-3$ PUFA did not cause a significant reduction in the risk of total mortality (RR $0.87 ; 95 \% \mathrm{CI}$ : 0.73-1.03) or combined CV events (RR 0.95; 95\% CI: 0.82-1.12). Considerable debate was generated by the choice of inclusion of the DART II (Burr et al., 2003) in the analysis, because of various limitations of the study and the difficulties occurring during its conduct (von Schacky et al., 2006; Graham et al., 2007; von Schacky and Harris, 2007). After excluding DART II from the Cochrane analysis, the reduction of total death became statistically significant (RR 0.83; 95\% CI: 0.75-0.91), although the risk of CV events did not change (Hooper et al., 2004). More recently a review, at variance with the previous ones, pooled the effect on SCD of eight trials, comprising 20,997 patients, and showed that the treatment with $n-3$ PUFA was able to significantly reduce the incidence of SCD (RR 0.43 ; 95\% CI: $0.20-0.91$ ) in post-MI patients. In patients with angina the risk of SCD was increased (RR 1.39; 95\% CI: 1.01-1.92) and overall, $n-3$ PUFA had no effect on cardiac death and all-cause mortality (RR 0.71 and 0.77 ; $95 \%$ CI: $0.50-1.00$ and $0.58-1.01$, respectively; Zhao et al., 2009). In 2010 a meta-analysis of 29 randomized controlled trials, comprising 35.144 patients, showed that $n-3$ PUFA treatment was not associated with a statistically significant decreased mortality (RR 0.88; 95\% CI: 0.64-1.03) although the probability of some benefits was high (0.93; Filion et al., 2010). A recent meta-analysis, including 20.485 patients with a history of CVD, showed that $n-3$ PUFA supplementation did not reduce the risk of overall CV events (RR 0.99; 95\% CI: 0.891.09), all-cause mortality, SCD, MI, HF, or transient ischemic attack and stroke (Kwak et al., 2012). About the results of this last meta-analysis several aspects deserve to be considered, e.g., most studies were very small, not designed to evaluate CV endpoints and with a short follow-up, the methodological choice of using 


\begin{tabular}{|c|c|c|c|c|c|c|}
\hline \multirow[t]{2}{*}{ study } & \multicolumn{2}{|c|}{ n-3 PUFA } & \multicolumn{2}{|c|}{ placebo } & \multirow{2}{*}{$\begin{array}{l}\text { weight } \\
\%\end{array}$} & \multirow{2}{*}{$\begin{array}{c}\text { Odds Ratio } \\
\mathrm{M}-\mathrm{H} \text {, fixed, }(95 \% \mathrm{Cl})\end{array}$} \\
\hline & events & total & events & total & & \\
\hline Leaf 11 & 44 & 200 & 66 & 202 & 25.6 & $0.58(0.37-0.91)$ \\
\hline Raitt ${ }^{12}$ & 51 & 100 & 41 & 100 & 10.0 & $1.50(0.86-2.62)$ \\
\hline SOFA ${ }^{13}$ & 75 & 273 & 81 & 273 & 29.4 & $0.90(0.62-1.30)$ \\
\hline GISSI-HF 14 & 76 & 278 & 98 & 288 & 35 & $0.73(0.51-1.04)$ \\
\hline
\end{tabular}

\begin{tabular}{|c|c|c|c|}
\hline total 246 & 851 & 286 & 863 \\
\hline Heterogeneity: & \multicolumn{3}{|c|}{$X^{2}=7.39, d f=3(P=0.06) ;\left.\right|^{2}=59$} \\
\hline
\end{tabular}

$0.82(0.67-1.01)$

effect:

$\mathrm{Z}=1.91(\mathrm{P}=0.06)$

Odds Ratio

$\mathrm{M}-\mathrm{H}$, Fixed, $95 \% \mathrm{Cl}$

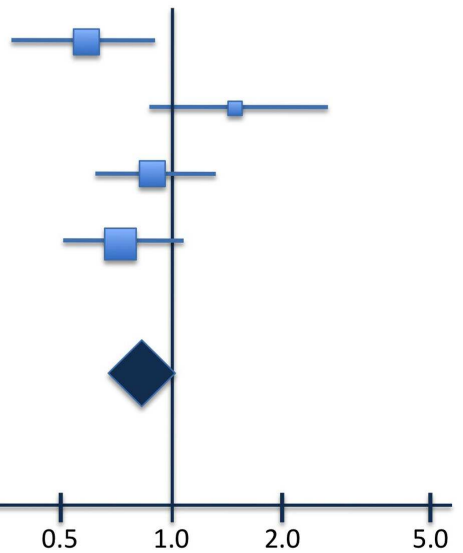

FIGURE 1 | Pooled analysis of the effect of n-3 PUFA on appropriate ICD intervention.

random-effects models in the primary analysis, and the exclusion of two large open-label trials (Gruppo Italiano per lo Studio della Sopravvivenza nell'Infarto miocardico, 1999; Yokoyama et al., 2007).

\section{CONCLUSION}

The evidence available to date seem to suggest $n-3$ PUFA having an antiarrhythmic effects, but no firm conclusion can be drawn. The stronger evidence on positive effects of $n-3$ PUFA in reducing SCD came from studies including patients with CHD. In patients with symptomatic HF, $n-3$ PUFA seem to reduce significantly ventricular arrhythmias and SCD. Such effect on ventricular arrhythmia has not been convincingly confirmed so far by the results of trials in carriers of an ICD, though the meta-analysis of the studies in ICD patients is very suggestive. On the other side, the effect on recurrent/new-onset AF is still controversial. Many of the

\section{REFERENCES}

Albert, C. M., Campos, H., Stampfer, M. J., Ridker, P. M., Manson, J. E., Willett, W. C., and Ma, J. (2002). Blood levels of long-chain n-3 fatty acids and the risk of sudden death. N. Engl. J. Med. 346, 1113-1118.

Albert, C. M., Hennekens, C. H., O’Donnell, C. J., Ajani, U. A., Carey, V. J., Willett, W. C., Ruskin, J. N., and Manson, J. E. (1998). Fish consumption and risk of sudden cardiac death. JAMA 279, 23-28.

Bang, H. O., and Dyerberg, J. (1972). Plasma lipids and lipoproteins in Greenlandic west coast Eskimos. Acta Med. Scand. 192, 85-94.

Bang, H. O., Dyerberg, J., and Nielsen, A. B. (1971). Plasma lipid and lipoprotein pattern in Greenlandic Westcoast Eskimos. Lancet 1, 1143-1145.
Barzi, F., Woodward, M., Marfisi, R. M., Tavazzi, L., Valagussa, F., and Marchioli, R. (2003). Mediterranean diet and all-causes mortality after myocardial infarction: results from the GISSI-Prevenzione trial. Eur. J. Clin. Nutr. 57, 604-611.

Billman, G. E., Kang, J. X., and Leaf, A. (1999). Prevention of sudden cardiac death by dietary pure omega- 3 polyunsaturated fatty acids in dogs. Circulation 99, 2452-2457.

Biscione, F., Totteri, A., De Vita, A., Lo Bianco, F., and Altamura, G. (2005). Effect of omega-3 fatty acids on the prevention of atrial arrhythmias. Ital. Heart J. Suppl. 6, 53-59.

Brouwer, I. A., Raitt, M. H., Dullemeijer, C., Kraemer, D. F., Zock, P. L., Morris, C., Katan, M. B., Connor,

clinical trials conducted so had not significant results. The main cause of this "failure" is the inadequate power of the studies due to either low rate of events or the overoptimistic expectations of the benefit of $n-3$ PUFA used for sample size calculation. Serum baseline levels of $n-3$ PUFA and different doses may have contributed to such results.

In conclusion, the still debated antiarrhythmic effect of $n-3$ PUFA needs to be investigated in larger and/or more efficient trials than those conducted so far. On this regard it is possible that a more accurate selection of patients, e.g., evaluating relevant biological parameters and markers (type and length of AF, left atrial dimensions, plasma and cellular $n-3$ PUFA levels, systemic inflammatory status, or oxidative stress), a standardization in the device programming in ICD patient populations, and a "realistic" sample size calculation might answer some of the still open question on the antiarrhythmic effect of $n-3$ PUFA.

W. E., Camm, J. A., Schouten, E. G., and Mcanulty, J. (2009). Effect of fish oil on ventricular tachyarrhythmia in three studies in patients with implantable cardioverter defibrillators. Eur. Heart J. 30, 820-826.

Brouwer, I. A., Zock, P. L., Camm, A. J., Bocker, D., Hauer, R. N., Wever, E. F., Dullemeijer, C., Ronden, J. E., Katan, M. B., Lubinski, A., Buschler, H., and Schouten, E. G. (2006). Effect of fish oil on ventricular tachyarrhythmia and death in patients with implantable cardioverter defibrillators: the Study on Omega-3 Fatty Acids and Ventricular Arrhythmia (SOFA) randomized trial. JAMA 295, 2613-2619.

Burr, M. L., Ashfield-Watt, P. A., Dunstan, F. D., Fehily, A. M., Breay, P.
Ashton, T., Zotos, P. C., Haboubi, N. A., and Elwood, P. C. (2003). Lack of benefit of dietary advice to men with angina: results of a controlled trial. Eur. J. Clin. Nutr. 57, 193-200.

Burr, M. L., Fehily, A. M., Gilbert, J. F., Rogers, S., Holliday, R. M., Sweetnam, P. M., Elwood, P. C., and Deadman, N. M. (1989). Effects of changes in fat, fish, and fibre intakes on death and myocardial reinfarction: diet and reinfarction trial (DART). Lancet 2, 757-761.

Calo, L., Bianconi, L., Colivicchi, F., Lamberti, F., Loricchio, M. L., de Ruvo, E., Meo, A., Pandozi, C., Staibano, M., and Santini, M. (2005). $\mathrm{N}-3$ fatty acids for the prevention of atrial fibrillation after coronary artery bypass surgery: a randomized, 
controlled trial. J. Am. Coll. Cardiol. 45, 1723-1728.

Camm, A. J., and Savelieva, I. (2011). Fish oil for secondary prevention of atrial fibrillation: should we still believe in its antiarrhythmic effect? Circulation 124, 1093-1096.

Christensen, J. H., Korup, E., Aaroe, J., Toft, E., Moller, J., Rasmussen, K., Dyerberg, J., and Schmidt, E. B. (1997). Fish consumption, n-3 fatty acids in cell membranes, and heart rate variability in survivors of myocardial infarction with left ventricular dysfunction. Am. J. Cardiol. 79, 1670-1673.

de Lorgeril, M., Renaud, S., Mamelle, N., Salen, P., Martin, J. L., Monjaud, I., Guidollet, J., Touboul, P., and Delaye, J. (1994). Mediterranean alpha-linolenic acid-rich diet in secondary prevention of coronary heart disease. Lancet 343, 1454-1459.

Filion, K. B., El Khoury, F., Bielinski, M., Schiller, I., Dendukuri, N., and Brophy, J. M. (2010). Omega3 fatty acids in high-risk cardiovascular patients: a meta-analysis of randomized controlled trials. BMC Cardiovasc. Disord. 10, 24. doi:10.1186/1471-2261-10-24

Finzi, A. A., Latini, R., Barlera, S., Rossi, M. G., Ruggeri, A., Mezzani, A., Favero, C., Franzosi, M. G., Serra, D., Lucci, D., Bianchini, F., Bernasconi, R., Maggioni, A. P., Nicolosi, G., Porcu, M., Tognoni, G., Tavazzi, L., and Marchioli, R. (2011). Effects of n-3 polyunsaturated fatty acids on malignant ventricular arrhythmias in patients with chronic heart failure and implantable cardioverterdefibrillators: a substudy of the Gruppo Italiano per lo Studio della Sopravvivenza nell'Insufficienza Cardiaca (GISSI-HF) trial. Am. Heart J. 161, 338-343.e331.

Galan, P., Kesse-Guyot, E., Czernichow, S., Briancon, S., Blacher, J., Hercberg, S., and Group, S. F. O. C. (2010). Effects of B vitamins and omega 3 fatty acids on cardiovascular diseases: a randomised placebo controlled trial. BMJ 341 , c6273.

Ghio, S., Scelsi, L., Latini, R., Masson, S., Eleuteri, E., Palvarini, M., Vriz, O., Pasotti, M., Gorini, M., Marchioli, R., Maggioni, A., Tavazzi, L., and Investigators, G.-H. (2010). Effects of $n-3$ polyunsaturated fatty acids and of rosuvastatin on left ventricular function in chronic heart failure: a substudy of GISSIHF trial. Eur. J. Heart Fail. 12, 1345-1353.
Graham, I., Atar, D., Borch-Johnsen, K., Boysen, G., Burell, G., Cifkova, R., Dallongeville, J., De Backer, G., Ebrahim, S., Gjelsvik, B., HerrmannLingen, C., Hoes, A., Humphries, S., Knapton, M., Perk, J., Priori, S. G., Pyorala, K., Reiner, Z., Ruilope, L., Sans-Menendez, S., Op Reimer, W. S., Weissberg, P., Wood, D., Yarnell, J., Zamorano, J. L., Walma, E., Fitzgerald, T., Cooney, M. T., Dudina, A., Vahanian, A., Camm, J., De Caterina, R., Dean, V., Dickstein, K., Funck-Brentano, C., Filippatos, G., Hellemans, I., Kristensen, S. D., Mcgregor, K., Sechtem, U., Silber, S., Tendera, M., Widimsky, P., Altiner, A., Bonora, E., Durrington, P. N., Fagard, R., Giampaoli, S., Hemingway, H., Hakansson, J., Kjeldsen, S. E., Larsen, M. L., Mancia, G., Manolis, A. J., Orth-Gomer, K., Pedersen, T., Rayner, M., Ryden, L., Sammut, M., Schneiderman, N., Stalenhoef, A. F., Tokgozoglu, L., Wiklund, O., and Zampelas, A. (2007). European guidelines on cardiovascular disease prevention in clinical practice: executive summary. Fourth Joint Task Force of the European Society of Cardiology and other societies on cardiovascular disease prevention in clinical practice (constituted by representatives of nine societies and by invited experts). Eur. J. Cardiovasc. Prev. Rehabil. 14(Suppl. 2), E1-E40.

Gruppo Italiano per lo Studio della Sopravvivenza nell'Infarto miocardico. (1999). Dietary supplementation with $n-3$ polyunsaturated fatty acids and vitamin $\mathrm{E}$ after myocardial infarction: results of the GISSI-Prevenzione trial. Lancet 354, 447-455.

He, K., Song, Y., Daviglus, M. L., Liu, K., Van Horn, L., Dyer, A. R., and Greenland, P. (2004). Accumulated evidence on fish consumption and coronary heart disease mortality: a meta-analysis of cohort studies. Circulation 109, 2705-2711.

Heart Protection Study Collaborative Group. (2002). MRC/BHF Heart Protection Study of cholesterol lowering with simvastatin in 20,536 high-risk individuals: a randomised placebo-controlled trial. Lancet 360, $7-22$.

Hooper, L., Thompson, R. L., Harrison, R. A., Summerbell, C. D., Moore, H., Worthington, H. V., Durrington, P. N., Ness, A. R., Capps, N. E., Davey Smith, G., Riemersma, R. A., and Ebrahim, S. B. (2004). Omega 3 fatty acids for prevention and treatment of cardiovascular disease. Cochrane Database Syst. Rev. CD003177.
Hooper, L., Thompson, R. L., Harrison, R. A., Summerbell, C. D., Ness, A. R., Moore, H. J., Worthington, H. V., Durrington, P. N., Higgins, J. P., Capps, N. E., Riemersma, R. A., Ebrahim, S. B., and Davey Smith, G. (2006). Risks and benefits of omega 3 fats for mortality, cardiovascular disease, and cancer: systematic review. BMJ 332, 752-760.

Iso, H., Kobayashi, M., Ishihara, J., Sasaki, S., Okada, K., Kita, Y., Kokubo, Y., and Tsugane, S. (2006). Intake of fish and n3 fatty acids and risk of coronary heart disease among Japanese: the Japan Public Health Center-Based (JPHC) Study Cohort I. Circulation 113, 195-202.

Jenkins, D. J., Josse, A. R., Beyene, J. Dorian, P., Burr, M. L., Labelle, R. Kendall, C. W., and Cunnane, S. C. (2008). Fish-oil supplementation in patients with implantable cardioverter defibrillators: a metaanalysis. CMAJ 178, 157-164.

Kang, J. X., and Leaf, A. (1994). Effects of long-chain polyunsaturated fatty acids on the contraction of neonatal rat cardiac myocytes. Proc. Natl. Acad. Sci. U.S.A. 91, 9886-9890.

Kang, J. X., and Leaf, A. (1995). Prevention and termination of beta-adrenergic agonist-induced arrhythmias by free polyunsaturated fatty acids in neonatal rat cardiac myocytes. Biochem. Biophys. Res. Commun. 208, 629-636.

Kang, J. X., and Leaf, A. (1996). Antiarrhythmic effects of polyunsaturated fatty acids. Recent studies. Circulation 94, 1774-1780.

Kang, J. X., Xiao, Y. F., and Leaf, A. (1995). Free, long-chain, polyunsaturated fatty acids reduce membrane electrical excitability in neonatal rat cardiac myocytes. Proc. Natl. Acad. Sci. U.S.A. 92, 3997-4001.

Kotseva, K., Wood, D., de Backer, G., de Bacquer, D., Pyorala, K., Keil U., and Group, E. S. (2009a). Cardiovascular prevention guidelines in daily practice: a comparison of EUROASPIRE I, II, and III surveys in eight European countries. Lancet 373, 929-940.

Kotseva, K., Wood, D., de Backer, G., de Bacquer, D., Pyorala, K., Keil, U., and EUROASPIRE Study Group. (2009b). EUROASPIRE III: a survey on the lifestyle, risk factors and use of cardioprotective drug therapies in coronary patients from 22 European countries. Eur. J. Cardiovasc. Prev. Rehabil. 16, 121-137.
Kowey, P. R., Reiffel, J. A., Ellenbogen, K. A., Naccarelli, G. V., and Pratt, C. M. (2010). Efficacy and safety of prescription omega-3 fatty acids for the prevention of recurrent symptomatic atrial fibrillation: a randomized controlled trial. JAMA 304, 2363-2372.

Kromhout, D., Giltay, E. J., Geleijnse, J. M., and Alpha Omega Trial Group. (2010). n-3 fatty acids and cardiovascular events after myocardial infarction. N. Engl. J. Med. 363, 2015-2026.

Kwak, S. M., Myung, S. K., Lee, Y. J., Seo, H. G., and For the Korean Meta-Analysis Study Gruop. (2012). Efficacy of omega-3 fatty acid supplements (eicosapentaenoic acid and docosahexaenoic acid) in the secondary prevention of cardiovascular disease: a meta-analysis of randomized, double-blind, placebocontrolled trials. Arch. Intern. Med. doi: 10.1001/archinternmed. 2012.262. [Epub ahead of print].

Leaf, A. (1999). Dietary prevention of coronary heart disease: the Lyon Diet Heart Study. Circulation 99, 733-735.

Leaf, A., Albert, C. M., Josephson, M. Steinhaus, D., Kluger, J., Kang, J. X., Cox, B., Zhang, H., and Schoenfeld, D. (2005). Prevention of fatal arrhythmias in high-risk subjects by fish oil n-3 fatty acid intake. Circulation 112, 2762-2768.

Leaf, A., Kang, J. X., Xiao, Y. F., and Billman, G. E. (2003). Clinical prevention of sudden cardiac death by $n-3$ polyunsaturated fatty acids and mechanism of prevention of arrhythmias by $\mathrm{n}-3$ fish oils. Circulation 107, 2646-2652.

Leon, H., Shibata, M. C., Sivakumaran, S., Dorgan, M., Chatterley, T., and Tsuyuki, R. T. (2008). Effect of fish oil on arrhythmias and mortality: systematic review. $B M J$ 337, a2931.

Liu, T., Korantzopoulos, P., Shehata, M., Li, G., Wang, X., and Kaul, S. (2011). Prevention of atrial fibrillation with omega- 3 fatty acids: a meta-analysis of randomised clinical trials. Heart 97, 1034-1040.

Macchia, A., Levantesi, G., Franzosi, M. G., Geraci, E., Maggioni, A. P., Marfisi, R., Nicolosi, G. L., Schweiger, C., Tavazzi, L., Tognoni, G., Valagussa, F., and Marchioli, R. (2005). Left ventricular systolic dysfunction, total mortality, and sudden death in patients with myocardial infarction treated with $\mathrm{n}-3$ polyunsaturated fatty acids. Eur. J. Heart Fail. 7, 904-909. 
Marchioli, R., Barzi, F., Bomba, E., Chieffo, C., di Gregorio, D., di Mascio, R., Franzosi, M. G., Geraci, E., Levantesi, G., Maggioni, A. P., Mantini, L., Marfisi, R. M., Mastrogiuseppe, G., Mininni, N., Nicolosi, G. L., Santini, M., Schweiger, C., Tavazzi, L., Tognoni, G., Tucci, C., and Valagussa, F. (2002). Early protection against sudden death by $\mathrm{n}-3$ polyunsaturated fatty acids after myocardial infarction: time-course analysis of the results of the Gruppo Italiano per lo Studio della Sopravvivenza nell'Infarto Miocardico (GISSI)-Prevenzione. Circulation 105, 1897-1903.

Marchioli, R., Silletta, M. G., Levantesi, G., and Pioggiarella, R. (2009). Omega-3 fatty acids and heart failure. Curr. Atheroscler. Rep. 11, 440-447.

Marckmann, P., and Gronbaek, M. (1999). Fish consumption and coronary heart disease mortality. A systematic review of prospective cohort studies. Eur. J. Clin. Nutr. 53, 585-590.

Marik, P. E., and Varon, J. (2009). Omega-3 dietary supplements and the risk of cardiovascular events: a systematic review. Clin. Cardiol. 32, 365-372.

McLennan, P. L., Bridle, T. M., Abeywardena, M. Y., and Charnock, J. S. (1992). Dietary lipid modulation of ventricular fibrillation threshold in the marmoset monkey. Am. Heart J. 123, 1555-1561.

McLennan, P. L., Bridle, T. M., Abeywardena, M. Y., and Charnock, J. S. (1993). Comparative efficacy of $\mathrm{n}-3$ and $\mathrm{n}-6$ polyunsaturated fatty acids in modulating ventricular fibrillation threshold in marmoset monkeys. Am. J. Clin. Nutr. 58, 666-669.

Mente, A., de Koning, L., Shannon, H. S., and Anand, S. S. (2009). A systematic review of the evidence supporting a causal link between dietary factors and coronary heart disease. Arch. Intern. Med. 169, 659-669.

Mozaffarian, D., Marchioli, R., Gardner, T., Ferrazzi, P., O'Gara, P., Latini, R., Libby, P., Lombardi, F., Macchia, A., Page, R., Santini, M., Tavazzi, L., and Tognoni, G. (2011). The omega-3 fatty acids for prevention of post-operative atrial fibrillation trial - rationale and design. Am. Heart J. 162, 56-63.e53.

Mozaffarian, D., and Rimm, E. B. (2006). Fish intake, contaminants, and human health: evaluating the risks and the benefits. JAMA 296, 1885-1899.
Nilsen, D. W., Albrektsen, G., Landmark, K., Moen, S., Aarsland, T., and Woie, L. (2001). Effects of a high-dose concentrate of n-3 fatty acids or corn oil introduced early after an acute myocardial infarction on serum triacylglycerol and HDL cholesterol. Am. J. Clin. Nutr. 74, 50-56.

Nodari, S., Triggiani, M., Campia, U., Manerba, A., Milesi, G., Cesana, B. M., Gheorghiade, M., and Dei Cas, L. (2011). n-3 polyunsaturated fatty acids in the prevention of atrial fibrillation recurrences after electrical cardioversion: a prospective, randomized study. Circulation 124, 1100-1106.

Pisters, R., Nieuwlaat, R., Prins, M. H., Le Heuzey, J. Y., Maggioni, A. P., Camm, A. J., Crijns, H. J., and For the Euro Heart Survey Investigators. (2012). Clinical correlates of immediate success and outcome at 1-year follow-up of real-world cardioversion of atrial fibrillation: the Euro Heart Survey. Europace. 14, 666-674.

Raitt, M. H., Connor, W. E., Morris, C., Kron, J., Halperin, B., Chugh, S. S., Mcclelland, J., Cook, J., Macmurdy, K., Swenson, R., Connor, S. L., Gerhard, G., Kraemer, D. F., Oseran, D., Marchant, C., Calhoun, D., Shnider, R., and McAnulty, J. (2005). Fish oil supplementation and risk of ventricular tachycardia and ventricular fibrillation in patients with implantable defibrillators: a randomized controlled trial. JAMA 293, 2884-2891.

Rauch, B., Schiele, R., Schneider, S., Diller, F., Victor, N., Gohlke, H., Gottwik, M., Steinbeck, G., del Castillo, U., Sack, R., Worth, H., Katus, H., Spitzer, W., Sabin, G., and Senges, J. (2010). OMEGA, a randomized, placebo-controlled trial to test the effect of highly purified omega- 3 fatty acids on top of modern guidelineadjusted therapy after myocardial infarction. Circulation 122, 2152-2159.

Rauch, B., Schiele, R., Schneider, S., Gohlke, H., Diller, F., Gottwik, M., Steinbeck, G., Heer, T., Katus, H., Zimmer, R., Erdogan, A., Pfafferott, C., and Senges, J. (2006). Highly purified omega-3 fatty acids for secondary prevention of sudden cardiac death after myocardial infarctionaims and methods of the OMEGAstudy. Cardiovasc. Drugs Ther. 20, 365-375.

Savelieva, I., Kakouros, N., Kourliouros, A., and Camm, A. J. (2011). Upstream therapies for management of atrial fibrillation: review of clinical evidence and implications for European Society of Cardiology guidelines. Part II: secondary prevention. Europace 13, 610-625.

Sellmayer, A., Witzgall, H., Lorenz, R. L., and Weber, P. C. (1995). Effects of dietary fish oil on ventricular premature complexes. Am. J. Cardiol. 76, 974-977.

Singh, R. B., Niaz, M. A., Sharma, J. P., Kumar, R., Rastogi, V., and Moshiri, M. (1997). Randomized, double-blind, placebo-controlled trial of fish oil and mustard oil in patients with suspected acute myocardial infarction: the Indian experiment of infarct survival 4. Cardiovasc. Drugs Ther. 11 485-491.

Siscovick, D. S., Raghunathan, T. E. King, I., Weinmann, S., Wicklund, K. G., Albright, J., Bovbjerg, V., Arbogast, P., Smith, H., Kushi, L. H., Cobb, L. A., Copass, M. K. Psaty, B. M., Lemaitre, R., Retzlaff, B., Childs, M., and Knopp, R. H. (1995). Dietary intake and cell membrane levels of long-chain n-3 polyunsaturated fatty acids and the risk of primary cardiac arrest. JAMA 274, 1363-1367.

Skuladottir, G. V., Heidarsdottir, R., Arnar, D. O., Torfason, B., Edvardsson, V., Gottskalksson, G., Palsson, R., and Indridason, O. S. (2011). Plasma n-3 and n- 6 fatty acids and the incidence of atrial fibrillation following coronary artery bypass graft surgery. Eur. J. Clin. Invest. 41, 995-1003.

Suzuki, T., Yamazaki, T., Ogawa, S., Nagai, R., Yamashita, T., and Investigators, J. R. I. (2011). Echocardiographic predictors of frequency of paroxysmal atrial fibrillation (AF) and its progression to persistent $\mathrm{AF}$ in hypertensive patients with paroxysmal AF: results from the Japanese Rhythm Management Trial II for Atrial Fibrillation (J-RHYTHM II Study). Heart Rhythm 8, 1831-1836.

Tavazzi, L., Maggioni, A. P., Marchioli, R., Barlera, S., Franzosi, M. G., Latini, R., Lucci, D., Nicolosi, G. L., Porcu, M., and Tognoni, G. (2008). Effect of n-3 polyunsaturated fatty acids in patients with chronic heart failure (the GISSI-HF trial): a randomised, double-blind, placebo-controlled trial. Lancet 372 , 1223-1230

Tavazzi, L., Tognoni, G., Franzosi, M. G., Latini, R., Maggioni, A. P., Marchioli, R., Nicolosi, G. L., and Porcu, M. (2004). Rationale and design of the GISSI heart failure trial: a large trial to assess the effects of $n-3$ polyunsaturated fatty acids and rosuvastatin in symptomatic congestive heart failure. Eur. J. Heart Fail. 6, 635-641.

The Long-Term Intervention with Pravastatin in Ischaemic Disease (LIPID) Study Group. (1998). Prevention of cardiovascular events and death with pravastatin in patients with coronary heart disease and a broad range of initial cholesterol levels. N. Engl. J. Med. 339, 1349-1357.

von Schacky, C., and Harris, W. S. (2007). Cardiovascular benefits of omega- 3 fatty acids. Cardiovasc. Res. 73, 310-315.

von Schacky, C., Harris, W. S., Mozaffarian, D., and Kris-Etherton, P. M. (2006). Response to Hoopers et al. Cochrane Review [Online]. Available at: http:// www.issfal.org/statements/hooperrebuttable [accessed September 16, 2009].

Xiao, Y. F., Gomez, A. M., Morgan, J. P., Lederer, W. J., and Leaf, A. (1997) Suppression of voltage-gated L-type $\mathrm{Ca} 2+$ currents by polyunsaturated fatty acids in adult and neonatal rat ventricular myocytes. Proc. Natl. Acad. Sci. U.S.A. 94, 4182-4187.

Xiao, Y. F., Kang, J. X., Morgan, J. P., and Leaf, A. (1995). Blocking effects of polyunsaturated fatty acids on $\mathrm{Na}+$ channels of neonatal rat ventricular myocytes. Proc. Natl. Acad. Sci. U.S.A. 92, 11000-11004.

Xiao, Y. F., Wright, S. N., Wang, G. K. Morgan, J. P., and Leaf, A. (1998). Fatty acids suppress voltage-gated $\mathrm{Na}+$ currents in HEK293t cells transfected with the alpha-subunit of the human cardiac $\mathrm{Na}+$ channel. Proc. Natl. Acad. Sci. U.S.A. 95, 2680-2685.

Yokoyama, M., Origasa, H., Matsuzaki, M., Matsuzawa, Y., Saito, Y., Ishikawa, Y., Oikawa, S., Sasaki, J., Hishida, H., Itakura, H., Kita, T., Kitabatake, A., Nakaya, N., Sakata, T., Shimada, K., and Shirato, K. (2007). Effects of eicosapentaenoic acid on major coronary events in hypercholesterolaemic patients (JELIS): a randomised open-label, blinded endpoint analysis. Lancet 369, 1090-1098.

Yusuf, S., Sleight, P., Pogue, J., Bosch, J., Davies, R., and Dagenais, G. (2000). Effects of an angiotensinconverting-enzyme inhibitor, ramipril, on cardiovascular events in high-risk patients. The Heart Outcomes Prevention Evaluation Study Investigators. N. Engl. J. Med. 342, 145-153. 
Zatonski, W., Campos, H., and Willett, W. (2008). Rapid declines in coronary heart disease mortality in Eastern Europe are associated with increased consumption of oils rich in alpha-linolenic acid. Eur. J. Epidemiol. 23, 3-10.

Zhao, Y. T., Chen, Q., Sun, Y. X., Li, X. B., Zhang, P., Xu, Y., and Guo, J. H. (2009). Prevention of sudden cardiac death with omega-3 fatty acids in patients with coronary heart disease: a meta-analysis of randomized controlled trials. Ann. Med. 41, 301-310.

Conflict of Interest Statement: Roberto Marchioli has been involved in the conduct of various large-scale trials assessing the effect of n-3 PUFA and received honoraria for lectures on n-e PUFA by various pharmaceutical companies.

Received: 06 March 2012; paper pending published: 09 April 2012; accepted: 22 May 2012; published online: 28 June 2012.

Citation: Marchioli $R$ and Levantesi G (2012) Why do we still need large scale clinical trial: the case of n-3 PUFA. Front. Physio. 3:202. doi: 10.3389/fphys.2012.00202
This article was submitted to Frontiers in Cardiac Electrophysiology, a specialty of Frontiers in Physiology.

Copyright (C) 2012 Marchioli and Levantesi. This is an open-access article distributed under the terms of the Creative Commons Attribution Non Commercial License, which permits non-commercial use, distribution, and reproduction in other forums, provided the original authors and source are credited. 